\title{
Phase analysis of gated PET in the evaluation of mechanical ventricular synchrony: A narrative overview
}

\author{
Luis Eduardo Juarez-Orozco, MD, PhD, ${ }^{\mathrm{a}}$ Andrea Monroy-Gonzalez, MD, ${ }^{\mathrm{b}}$ \\ Niek H. J. Prakken, MD, PhD, ${ }^{b}$ Walter Noordzij, MD, PhD, ${ }^{\mathrm{b}}$ Juhani Knuuti, MD, \\ PhD, ${ }^{a}$ Robert A. deKemp, PhD, ${ }^{c}$ and Riemer H. J. A. Slart, $M D, P^{b / d}$ \\ a Turku PET Centre, University of Turku and Turku University Hospital, Turku, Finland \\ b Department of Nuclear Medicine and Molecular Imaging, University Medical Center Gronin- \\ gen, University of Groningen, Groningen, The Netherlands \\ c Division of Cardiology, Department of Medicine, National Cardiac PET Centre, University of \\ Ottawa Heart Institute (UOHI), University of Ottawa, Ottawa, ON, Canada \\ d Biomedical Photonic Imaging, Technical Medical Centre, University of Twente, Enschede, The \\ Netherlands
}

Received Jan 7, 2019; accepted Feb 5, 2019

doi: $10.1007 / \mathrm{s} 12350-019-01670-7$

Noninvasive imaging modalities offer the possibility to dynamically evaluate cardiac motion during the cardiac cycle by means of ECG-gated acquisitions. Such motion characterization along with orientation, segmentation preprocessing, and ultimately, phase analysis, can provide quantitative estimates of ventricular mechanical synchrony. Current evidence on the role of mechanical synchrony evaluation is mainly available for echocardiography and gated singlephoton emission computed tomography, but less is known about the utilization of gated positron emission tomography (PET). Although data available are sparse, there is indication that mechanical synchrony evaluation can be of diagnostic and prognostic values in patients with known or suspected coronary artery disease-related myocardial ischemia, prediction of response to cardiac resynchronization therapy, and estimation of risk for adverse cardiac events in patients' heart failure. As such, the evaluation of mechanical ventricular synchrony through phase analysis of gated acquisitions represents a value addition to modern cardiac PET imaging modality, which warrants further research and development in the evaluation of patients with cardiovascular disease. (J Nucl Cardiol 2019;26:1904-13.)

Key Words: Ventricular synchrony $\cdot$ phase analysis $\cdot$ gated PET

Electronic supplementary material The online version of this article (https://doi.org/10.1007/s12350-019-01670-7) contains supplementary material, which is available to authorized users.

The authors of this article have provided a PowerPoint file, available for download at SpringerLink, which summarises the contents of the paper and is free for re-use at meetings and presentations. Search for the article DOI on SpringerLink.com.
Reprint requests: Riemer H. J. A. Start MD, PhD, Department of Nuclear Medicine and Molecular Imaging, University Medical Center Groningen, University of Groningen, Hanzeplein 1, P.O. Box 30001, 9700 RB, Groningen, The Netherlands; r.h.j.a.slart@umcg.nl $1071-3581 / \$ 34.00$

Copyright (C) 2019 The Author(s) 


\begin{tabular}{|ll|}
\hline Abbreviations \\
BW & Bandwidth \\
CAD & Coronary artery disease \\
CMR & Cardiac magnetic resonance \\
CRT & Cardiac resynchronization therapy \\
E & Entropy \\
HF & Heart failure \\
LVEF & Left ventricular ejection fraction \\
MBF & Myocardial blood flow \\
MFR & Myocardial flow reserve \\
PET & Positron emission tomography \\
SD & Standard deviation \\
SPECT & Single-photon emission computed \\
& tomography \\
SRS & Summed rest score \\
\hline
\end{tabular}

See related editorial, pp. 1914-1917

\section{INTRODUCTION}

Beyond their capabilities to characterize myocardial architecture, perfusion, viability, and function, noninvasive imaging modalities offer the added possibility to dynamically evaluate ventricular motion during the cardiac cycle by means of ECG-gated acquisitions. ${ }^{1,2}$ Such motion characterization is achieved through sequential target detection, cavity orientation, segmentation preprocessing, and motion analysis resulting in quantitative estimates of ventricular mechanical synchrony. ${ }^{3}$

Currently, evidence on the evaluation of mechanical synchrony is mainly available for echocardiography, equilibrium radionuclide angiocardiography ${ }^{4}$ and gated single-photon emission computed tomography (SPECT), while fewer reports have focused on the utilization of gated positron emission tomography (PET). The principles, parameters, and available evidence on the use of PET imaging for mechanical synchrony evaluation are summarized in this review.

\section{CARDIAC GATED PET}

PET represents a state-of-the-art modality in cardiac imaging that allows the evaluation of quantitative physiological parameters (e.g., myocardial blood flow, glucose uptake, and oxidative metabolism) determined by the selected radiotracer. The intrinsic advantages of PET in comparison to SPECT technology such as higher count rates, more physiological tracers, and increased spatial resolution provide high-quality and quantitative images that boost the diagnostic and prognostic utility at a reasonable radiation burden.
Current PET scanners operate with list-mode acquisitions in order to obtain adequate datasets for the reconstruction of dynamic, static, and particularly (ECG-) gated images. The latter considers the ECG signal obtained in parallel to the acquisition and tracks wall thickening and changes in the detected cavity contours throughout the averaged cardiac cycle, typically binned into 8 or 16 frames (notably, phantom research has demonstrated that 8 or 16 frames per cycle Fourier phase analysis is equally effective to detect phase delays as with 64 frames per cycle non-Fourier analysis ${ }^{5}$ ). This processing provides quantitative estimations of left-ventricular cavity volumes and consequently, the derived left ventricular ejection fraction (LVEF) ${ }^{6,7}$ Thereon, a distinctive evaluation can be performed in order to estimate parameters of ventricular synchrony of contraction through phase analysis as illustrated in Figure 1.

\section{PHASE ANALYSIS FOR VENTRICULAR SYNCHRONY}

Phase analysis was developed originally by Chen and colleagues, ${ }^{8}$ and has become an interesting valueadded tool in nuclear imaging. In such analysis, a large number of transmural regions in the left ventricular myocardium (500-1000) are sampled by evaluating the myocardial counts detected throughout the re-binned frames of the averaged cardiac cycle. These threedimensional count distributions are analyzed using a first-harmonic Fourier (sinusoidal) function (Figure 1) for every sample of the myocardium. This allows for the measurement of the phase offset and amplitude, which provides an index of myocardial wall thickening. The phase offset shows the difference between the start-time of the first frame and the time when the sinusoidal function crosses the DC component of the myocardial counts, which represents the average value of mechanical contraction for a particular pixel. This point of convergence is interpreted as the moment of onset of the ventricular contraction for the considered sample. Finally, the collection of all phase offsets corresponding with every spatial sample can be displayed in a colorcoded histogram with an $x$-axis standardized to the length of the average cardiac cycle expressed in milliseconds, periodic degrees, or a relative percentage. Moreover, it is also possible to track the onset of mechanical relaxation from a multiharmonic analysis with count-drop correction, which would correspond with the diastolic mechanical synchrony. ${ }^{5}$ This last approach, however, has not been significantly evaluated in PET imaging.

The resulting phase histogram provides several descriptive parameters of the synchronicity and 


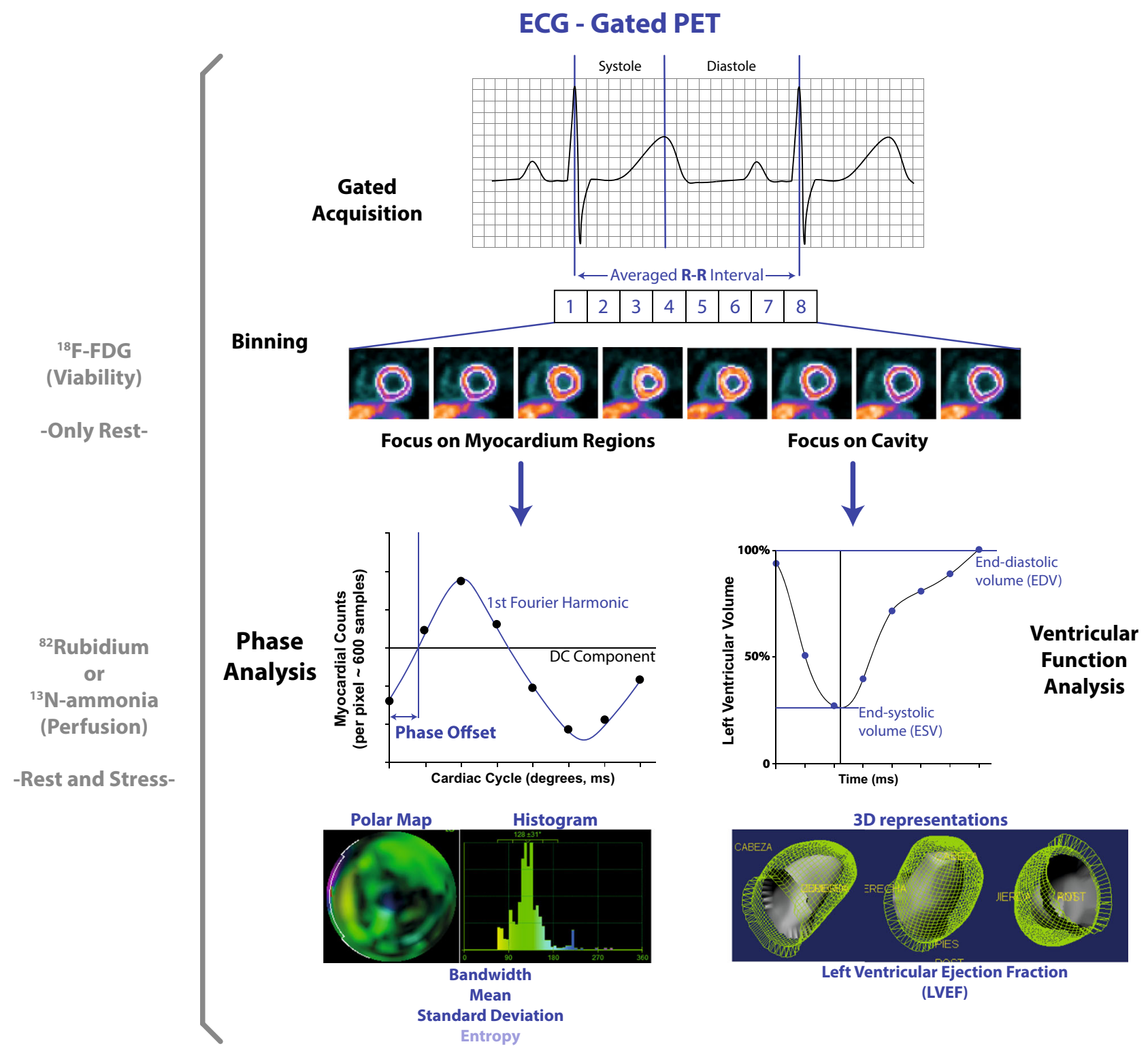

Figure 1. Phase and volume analyses of ECG-gated PET. DC represents the average value of mechanical contraction for a particular pixel.

uniformity of contraction of the left ventricle (see Figure 2), both as a whole or following standard segmentation procedures. Described parameters include phase mean, phase standard deviation (SD), phase bandwidth $(\mathrm{BW}=1.96 \times \mathrm{SD})$, synchrony $(\mathrm{S})$, and entropy (E). ${ }^{9}$ The phase mean and SD represent the average moment of phase offsets in the whole LV and the corresponding standard deviation over all myocardial samples. Phase bandwidth represents the interval where $95 \%$ of the values occur in the histogram (i.e., the range during which $95 \%$ of the ventricle initiates mechanical contraction). Entropy and Synchrony, as proposed by O'Connell et $\mathrm{al}^{10}$ for planar imaging, then generalized to SPECT, ${ }^{11,12}$ are slightly different metrics combining the amplitude and phase of dyssynchrony during ventricular contraction, not influenced by the histogram borders or by phase similarity. ${ }^{13}$

Since the average cycle is obtained over several hundreds of gated cardiac cycles (multiple R-R intervals), it is possible that phase analysis may be affected when substantial rhythm or motion disturbances are encountered (e.g., in patients with atrial fibrillation or 


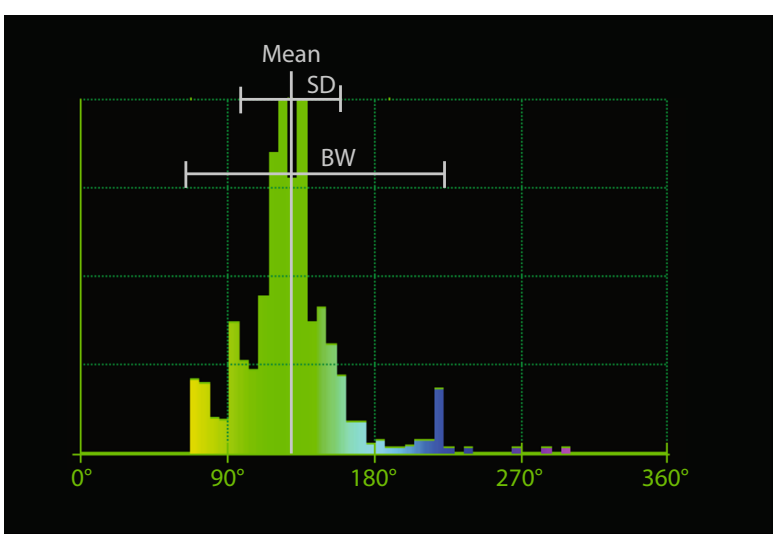

Figure 2. Phase histogram used to define the average onset of contraction (mean), and regional standard deviation (SD) and bandwidth (BW).

frequent ventricular extrasystoles). ${ }^{14-16}$ Correction techniques of gating errors are therefore warranted in order to obtain robust measurements in clinical practice. ${ }^{17}$

\section{PET VENTRICULAR SYNCHRONY STUDIES}

In contrast with SPECT, there is a relative paucity of publications on the feasibility, validation, average parameter values in populations of interest, and clinical utility regarding PET (dys)synchrony imaging, as evidenced in Table 1. Focus has been placed in the utility of PET synchrony assessment for the distinction of patients who may benefit from cardiac resynchronization therapy (CRT) considering that the rate of nonresponders has stabilized at around $30 \%$ of patients, as selected by ECG, LVEF, and clinical heart failure (HF) criteria following current guidelines. ${ }^{15,18}$ In the setting of CAD, the link between myocardial ischemia and mechanical synchrony has been studied primarily under the working assumption that myocardial blood flow (the quantitative perfusion feature offered by PET but not SPECT imaging) may represent a determinant in the status of ventricular mechanical synchrony and its response during pharmacological stress (vide infra).

A large number of published reports on mechanical ventricular synchrony evaluated with PET have utilized ${ }^{18} \mathrm{~F}-\mathrm{FDG}$ and ${ }^{82} \mathrm{Rb}$ as viability and perfusion radiotracers, respectively. In fact, only one study has evaluated correlates and determinants of synchrony measurements from ${ }^{13} \mathrm{~N}$-ammonia PET perfusion data, ${ }^{19}$ while no study has utilized ${ }^{15} \mathrm{O}$-water for such evaluation.

\section{Predictors of PET Ventricular Synchrony}

A number of variables have been proposed to associate with mechanical dyssynchrony in retrospective studies such as QRS duration (as the surrogate for electrical dyssynchrony), intraventricular conduction delay (as seen in patients with left bundle branch block [LBBB]) and LVEF. ${ }^{20}$ With PET imaging particularly, sex, age, the presence of type- 2 diabetes mellitus, and impaired quantitative stress myocardial perfusion have demonstrated an independent effect on a constellation of PET-derived ventricular function parameters that included Entropy ${ }^{19}$ in patients with known or suspected CAD. Additionally, in patients with HF, the degree of ventricular remodeling, perfusion defect size, atrial fibrillation, BMI and LVEF have been reported as independent predictors of mechanical synchrony (evaluated using phase SD). ${ }^{21}$ These data underline how a different but overlapping range of relevant predictors of dyssynchrony may be considered according to the clinical scenario.

\section{Role in Coronary Artery Disease}

A parallel working concept in the field of cardiac PET deals with the relationship between myocardial ischemia and ventricular synchrony. ${ }^{19,22,23}$ Notably, the characterization of this interaction seems to be suitable for the application of PET due to the fact that myocardial perfusion studies are typically acquired during conditions of peak-stress (in contrast to the poststress evaluation with SPECT imaging). Phase synchrony evaluation has therefore been proposed as a marker in the detection of myocardial stunning and ischemia-induced dyssynchrony. ${ }^{24}$ Specifically, synchrony differences in between rest and stress acquisitions have been demonstrated. Synchrony indices have been found to be lower during peak stress in patients with normal myocardial perfusion possibly due to improved contractility. Interestingly, these differences have been described in patients with normal and low LVEF. ${ }^{16}$ Figure 3 depicts representative examples of PET-measured ventricular synchrony along the continuum of ischemic heart disease.

Although SPECT studies have aimed to better characterize the phenomenon, ${ }^{25}$ it is still unknown how the perfusion-synchrony relation may operate at the regional level with the utilization of PET. Moreover, it is also unclear to what extent may the evaluation of PET synchrony improve the detection of significant CAD beyond other robust functional variables such as LVEF.

\section{Role in Heart Failure and CRT Response Prediction}

In patients with HF who may ultimately attract criteria for the indication of $\mathrm{CRT}^{18}$ (i.e., $\mathrm{LVEF} \leq 35 \%$, 


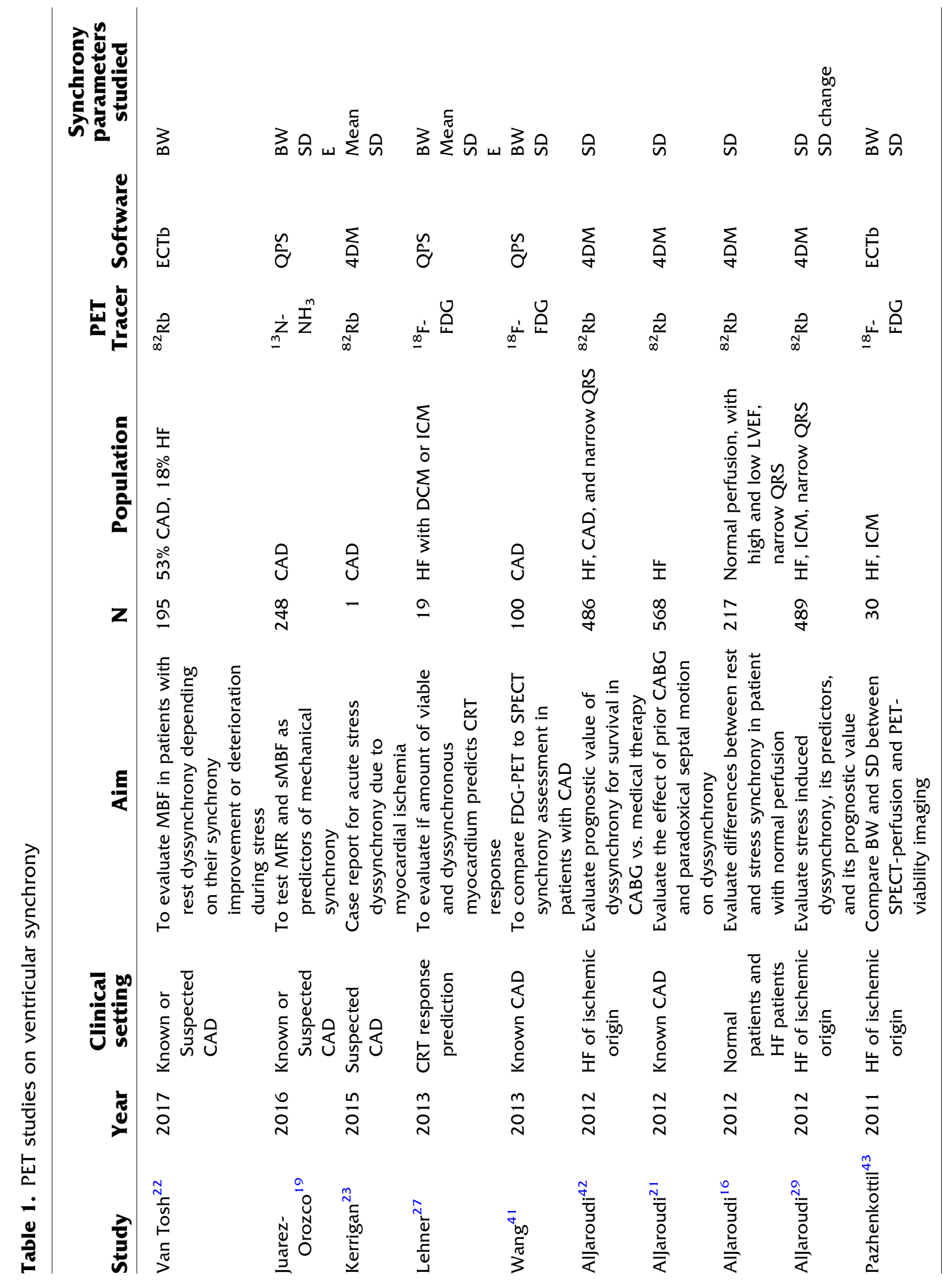


QRS $>150 \mathrm{~ms}$, and NYHA functional classification $\geq$ II), there is a notion that a proportion of effective response to CRT could be explained by an underlying substrate of mechanical dyssynchrony (which is not evaluated in formal selection of CRT recipients, but only partially captured by the electrical synchrony criteria). Suggested variables have been proposed to associate with adequate response to the therapy such as location and extent of PET-defined myocardial viability, extent of scarring and optimal lead placement, LV volumes, and indeed, ventricular mechanical dyssynchrony. ${ }^{13,26,27}$ The challenge to effectively integrate every relevant PET-derived variable to refine CRT patient selection in a medium-to-large scale study remains ubiquitous.

\section{Prognostic Value of PET Synchrony Evaluation}

Only a handful of studies performed with PET have addressed the potential prognostic value of mechanical synchrony. The results of this very discrete body of evidence are inclined to be in favor of a discernible independent hazard ratio of synchrony measures as predictors of all-cause mortality in patients with ischemic cardiomyopathy, ${ }^{28}$ and patients with $\mathrm{HF}$ and a narrow QRS $\left(1.16[1.03,1.30]\right.$ per $10^{\circ}$ increase in SD and $1.19[1.01,1.38]$ per $10^{\circ}$ increase in SD response). ${ }^{21,29}$

\section{REFERENCE VALUES}

Table 2 outlines the reports that have suggested reference values (i.e., normal values and cutoff points for distinguishing from pathological populations) in the evaluation of mechanical synchrony with PET and SPECT (selected for comparison). In fact, when analyzing available reports, it is noticeable how assumptions of robustness, and in some cases of normal values, have been directly translated from SPECT studies. Although it is true that PET could be understood as a refined version of SPECT imaging due to lower noise, higher tracer counts, lower radiation burden, and improved spatial resolution, ${ }^{15}$ it is of great relevance to characterize how these factors may influence the estimation of normal and pathological synchrony values in order to promote the utilization of PET synchrony evaluation with different protocols and software packages. In this sense, the study by Cooke et al complementarily compared their estimates to those suggested in previous SPECT studies concluding that very likely $\mathrm{BW}$ and $\mathrm{SD}$ are robust and reproducible measures of synchrony across stressors, physiologic states, acquisitions, reconstruction methodologies, and 
Normal Quantitative Myocardial Perfusion

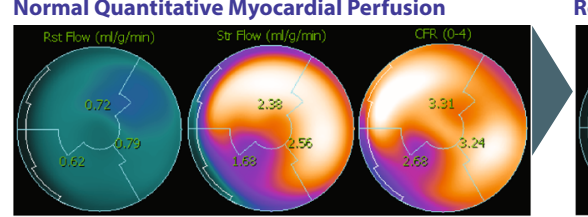

Rest Phase Analysis

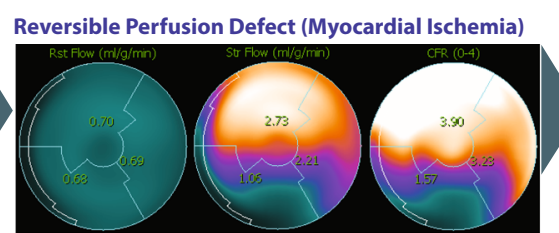

Rest Phase Analysis

Stress Phase Analysis

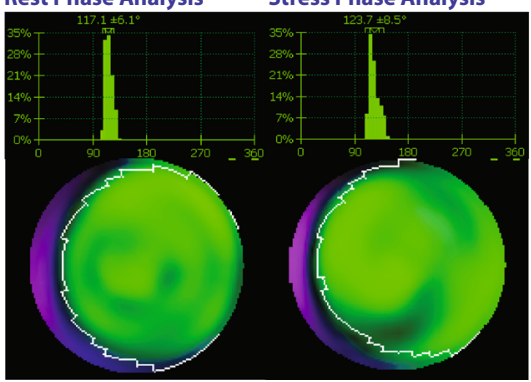

Fixed Perfusion Defect (Previous Myocardial Infarct

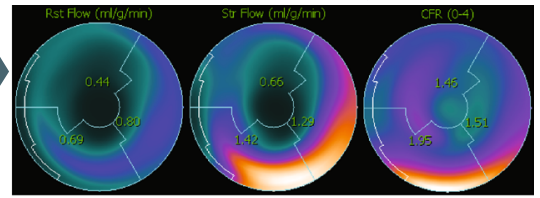

Rest Phase Analysis
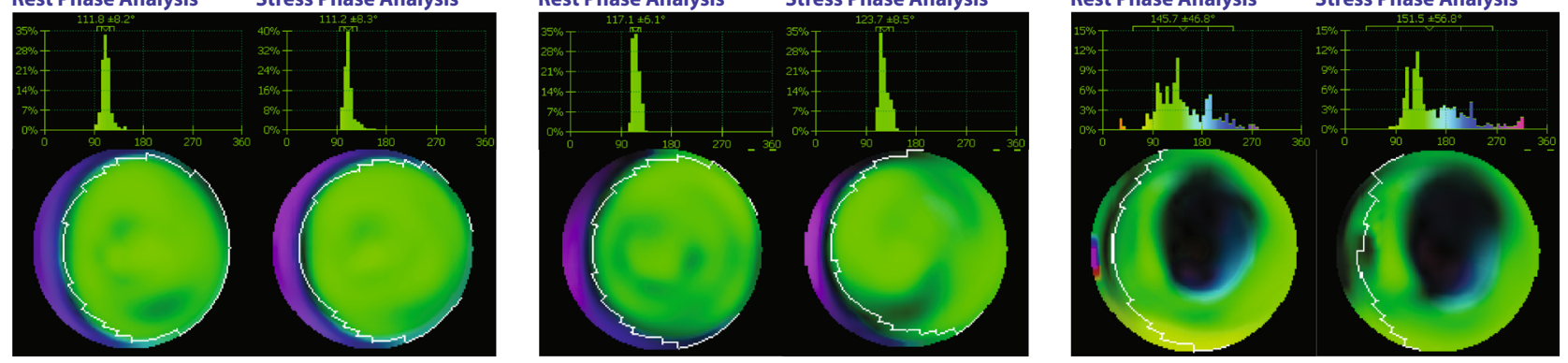

Figure 3. Phase synchrony evaluation in patients along the spectrum of ischemic heart disease (left panel: normal perfusion, middle panel: severe inferoseptal myocardial ischemia, and right panel: with previous anteroapical transmural myocardial infarction and moderate residual ischemia). Delayed onset of contraction is typically observed in the regions of ischemia and infarction.

processing algorithms. ${ }^{30}$ Further in general, factors like age, LVEF, and heart rate may affect the dyssynchrony results. SPECT studies have reported variability in volumes and ejection fraction by different software. ${ }^{31,32}$ Also, larger values of phase bandwidth, phase SD, and entropy have been reported for men compared to women in SPECT studies. ${ }^{33,34}$ These assumptions, however, should be utilized with caution when evaluating PETderived synchrony.

Another factor of interest is the availability of several commercial software packages that offer phase analysis. Overall, phase analysis has been implemented in the Emory Cardiac Toolbox 4DM and QGS software. Variability across packages has recently been addressed by Okuda et $\mathrm{al}^{35}{ }^{35}$ but only in the case of SPECT acquisitions. Cross-validation efforts in synchrony evaluation with PET are therefore warranted to enable comparison of measured values between imaging centers using different software programs.

In summary, ventricular mechanical synchrony as measured by PET imaging may be of value in the evaluation of patients with suspected myocardial ischemia leading to myocardial stunning and in patients with HF with an indication for CRT due to the suspected substrate of mechanical dyssynchrony. At the same time, it is likely that PET synchrony evaluation may hold prognostic values in patients with $\mathrm{HF}$ and in patients with CAD, in particular with multivessel disease $\mathrm{BW}$ of which and the SD of the phase after exercise are significantly increased. In addition, phase analysis is able to detect the LV mechanical dyssynchrony due to the vasomotion changes associated with occult atherosclerosis in patients with normal coronary angiography findings. Whether PET-measured synchrony can offer diagnostic value beyond or at an earlier stage than mainstream functional parameters, may serve as a tool for refining selection of CRT recipients, and should be incorporated in the clinical exercise of risk stratification, remains to be elucidated. The application of PET synchrony evaluation together with the evaluation of myocardial scar (fibrosis) has the potential to improve selection for access to CRT in those patients most likely to improve the clinical effectiveness and cost effectiveness of CRT for heart failure.

Notably, the intrinsic advantages of PET, including its wide range of physiological radiotracers available and its full quantitative capabilities, set the ground for the value addition to the phase analysis of ventricular synchrony in establishing the so-called "one-stop shop" 15 in which perfusion or viability, scar location, and extent, ventricular volumes, and function (both systolic and diastolic), and synchrony ${ }^{36}$ can be simultaneously evaluated. Moreover, comprehensive imaging can be boosted through the utilization of currently available hybrid equipment (PET/CT and PET/MR) that allows for complementary anatomic information (e.g., epicardial fat, calcium score, and venous system structure) to be obtained within the same imaging session. Cardiac MR (CMR) is, in addition to PET, is expected to provide - partly confirming, partly complementarytissue-specific anatomic (fiber, fat, muscle, and blood) and pathophysiological (edema, infarction, microvascular obstruction, and tumor) information, and could add tissue strain data which can be used as a measure of 
Table 2. Reference values and discrimination cutoffs

\begin{tabular}{|c|c|c|c|c|c|c|}
\hline Technique & Study & Year & Sample & Software & Normal values & Cutoff points \\
\hline SPECT & Okuda $^{35}$ & 2017 & $\begin{array}{l}122 \text { normal } \\
\text { perfusion and } \\
\text { LVEF, } 34 \text { with } \\
\text { suspected } \\
\text { dyssynchrony }\end{array}$ & $\begin{array}{l}\text { CardioREPO } \\
\text { 4DM } \\
\text { ECTb } \\
\text { QGS }\end{array}$ & $\begin{array}{l}\mathrm{BW}=38.4^{\circ} \pm 10.4 \\
\mathrm{SD}=9.7^{\circ} \pm 2.8 \\
\mathrm{E}=41.9 \% \pm 6.2\end{array}$ & $\begin{array}{l}\mathrm{BW}=24-42^{\circ} \\
\mathrm{SD}=8.6^{\circ}-15.3^{\circ} \\
\mathrm{E}=31-48 \%\end{array}$ \\
\hline PET & Aljaroudi ${ }^{16}$ & 2012 & $\begin{array}{l}91 \text { normal } \\
\text { perfusion and } \\
\text { LVEF, } 126 \text { with } \\
\text { low LVEF }\end{array}$ & 4DM & $\begin{array}{l}\mathrm{rSD}=16.8^{\circ} \pm 7.8 \\
\mathrm{sSD}=12.4^{\circ} \pm 3.7\end{array}$ & $\mathrm{SD}=20^{\circ}$ \\
\hline PET & Cooke $\mathrm{e}^{30}$ & 2011 & $\begin{array}{l}40 \text { low likelihood } \\
\text { of CAD ( } 20 \text { men } \\
\text { and } 20 \text { women) } \\
\text { and } 23 \text { with } \\
\text { LBBB ( } 10 \text { men } \\
\text { and } 13 \text { women) }\end{array}$ & ECTЬ & $\begin{array}{l}\text { Men } \\
\mathrm{rBW}=50.8^{\circ} \pm 18.7 \\
\mathrm{sBW}=38.1^{\circ} \pm 13.3 \\
\mathrm{rSD}=22.7^{\circ} \pm 13.2 \\
\mathrm{sSD}=15.0^{\circ} \pm 7.0 \\
\text { Women } \\
\mathrm{rBW}=44.4^{\circ} \pm 44.9 \\
\mathrm{sBW}=32.0^{\circ} \pm 13.5 \\
\mathrm{rSD}=16.6^{\circ} \pm 14.3 \\
\mathrm{sSD}=13.2^{\circ} \pm 7.7\end{array}$ & $\begin{array}{l}\text { Men } \\
\mathrm{rBW}=49^{\circ} \\
\mathrm{sBW}=52^{\circ} \\
\mathrm{rSD}=22.1^{\circ} \\
\mathrm{sSD}=26.1^{\circ} \\
\text { Women } \\
\mathrm{rBW}=50^{\circ} \\
\mathrm{sBW}=33^{\circ} \\
\mathrm{rSD}=15.7^{\circ} \\
\mathrm{sSD}=13.7^{\circ}\end{array}$ \\
\hline SPECT & Boogers ${ }^{44}$ & 2009 & $\begin{array}{l}40 \text { HF with CRT } \\
\text { indication ( } 24 \\
\text { CRT responders } \\
\text { and } 16 \\
\text { nonresponders) }\end{array}$ & QGS & - & $\begin{array}{l}\mathrm{BW}=72.5^{\circ} \\
\mathrm{SD}=19.6^{\circ}\end{array}$ \\
\hline SPECT & Henneman ${ }^{45}$ & 2007 & $\begin{array}{l}42 \text { HF with CRT } \\
\text { indication ( } 30 \\
\text { CRT responders } \\
\text { and } 12 \\
\text { nonresponders) }\end{array}$ & ECTb & - & $\begin{array}{l}\mathrm{BW}=135^{\circ} \\
\mathrm{SD}=43^{\circ}\end{array}$ \\
\hline SPECT & Chen $^{8}$ & 2005 & $\begin{array}{l}90 \text { low likelihood } \\
\text { of CAD ( } 45 \text { men } \\
\text { and } 45 \text { women) }\end{array}$ & ECTЬ & $\begin{array}{l}\text { Men } \\
\text { BW }=38.7^{\circ} \pm 11.8 \\
\text { SD }=14.2^{\circ} \pm 5.1 \\
\text { Women } \\
\text { BW }=30.6^{\circ} \pm 9.6 \\
\text { SD }=11.8^{\circ} \pm 5.2\end{array}$ & $\begin{array}{l}\text { Men } \\
\text { BW }=38.7^{\circ} \pm 11.8 \\
\text { SD }=14.2^{\circ} \pm 5.1 \\
\text { Women } \\
\text { BW }=30.6^{\circ} \pm 9.6 \\
\text { SD }=11.8^{\circ} \pm 5.2\end{array}$ \\
\hline
\end{tabular}

$B W$, bandwidth; $C A D$, coronary artery disease; $C R T$, cardiac resynchronization therapy; $E$, entropy; ECTb, Emory Cardiac Toolbox; $H F$, heart failure; $L B B B$, left bundle branch block; $L V E F$, left ventricular ejection fraction; $r$, rest; $s$, stress; $S D$, standard deviation

cardiac synchrony to complete a disease-specific cardiac model, as was recently reported for a carotid plaque inflammation model using MR-PET/CT, ${ }^{37}$ and in a cardiac sarcoidosis model using CMR, PET, and ultrasound, ${ }^{38}$ and in a hypertrophic cardiomyopathy $(\mathrm{HCM})$ phenotype model using CMR, PET, and ultrasound. ${ }^{39}$ The recently published joint position statement of the ESCR and EANM also states application of CMR-PET is feasible, robust, and promising. ${ }^{40}$ We therefore expect cardiac gated CMR-PET to provide a new model to help understand cardiac synchrony in future studies.

\section{NEW KNOWLEDGE GAINED}

Evaluation of PET ventricular mechanical synchrony has arguably emerged as an extrapolation of prior phase analysis using SPECT imaging. As such, there are variations in reference values, and extensive 
evidence on its utility for the evaluation of ventricular dysfunction with diagnostic and prognostic purposes as well as for better selection of CRT recipients is slowly emerging.

\section{CONCLUSION}

The evaluation of mechanical ventricular synchrony through phase analysis of gated acquisitions represents a value addition to modern cardiac PET imaging. Cardiac PET synchrony may be useful in the assessment of patients with $\mathrm{CAD}$, in the evaluation of prognosis in patients with cardiac dysfunction, and in the optimization of patient selection for advanced therapies such as CRT.

\section{Disclosure}

Dr. Juarez-Orozco, Dr. Gonzalez-Monroy, Dr. Prakken, Dr. Noordzij, Prof. Knuuti, Prof. deKemp and Prof. Slart have no relevant disclosures.

\section{Open Access}

This article is distributed under the terms of the Creative Commons Attribution 4.0 International License (http://creativ ecommons.org/licenses/by/4.0/), which permits unrestricted use, distribution, and reproduction in any medium, provided you give appropriate credit to the original author(s) and the source, provide a link to the Creative Commons license, and indicate if changes were made.

\section{References}

1. Mizunobu M, Sakai J, Sasao H, Murai H, Fujiwara H. Assessment of Left Ventricular Systolic and Diastolic Function Using ECGGated Technetium-99 m Tetrofosmin Myocardial Perfusion SPECT Comparison With Ultrasound Echocardiography. Int Hear J 2013;54:212-5.

2. Schaefer WM, Lipke CSA, Standke D, Kühl HP, Nowak B, Kaiser $\mathrm{H}-\mathrm{J}$, et al. Quantification of left ventricular volumes and ejection fraction from gated $99 \mathrm{mTc}-\mathrm{MIBI}$ SPECT: MRI validation and comparison of the Emory Cardiac Tool Box with QGS and 4DMSPECT. J Nucl Med 2005;46:1256-63.

3. Yamashita K, Tamaki N, Yonekura Y, Ohtani H, Saji H, Mukai T, et al. Quantitative analysis of regional wall motion by gated myocardial positron emission tomography: Validation and comparison with left ventriculography. J Nucl Med 1989;30:1775-86.

4. Singh H, Singhal A, Sharma P, Patel CD, Seth S, Malhotra A. Quantitative assessment of cardiac mechanical synchrony using equilibrium radionuclide angiography. J Nucl Cardiol 2013;20:415-25.

5. Galt JR, Garcia EV, Robbins WL. Effects of myocardial wall thickness on SPECT quantification. IEEE Trans Med Imaging 1990;9:144-50.

6. Hickey KT, Sciacca RR, Bokhari S, Rodriguez O, Chou R-L, Faber TL, et al. Assessment of cardiac wall motion and ejection fraction with gated PET using N-13 ammonia. Clin Nucl Med 2004;29:243-8

7. Slart RHJ, Bax JJ, de Jong RM, de Boer J, Lamb HJ, Mook PH, et al. Comparison of gated PET with MRI for evaluation of left ventricular function in patients with coronary artery disease. J Nucl Med 2004;45:176-82.

8. Chen J, Garcia EV, Folks RD, Cooke CD, Faber TL, Tauxe EL, et al. Onset of left ventricular mechanical contraction as determined by phase analysis of ECG-gated myocardial perfusion SPECT imaging: Development of a diagnostic tool for assessment of cardiac mechanical dyssynchrony. J Nucl Cardiol 2005;12:68795.

9. Germano G, Kavanagh PB, Slomka PJ, Van Kriekinge SD, Pollard G, Berman DS. Quantitation in gated perfusion SPECT imaging: The Cedars-Sinai approach. J Nucl Cardiol 2007;14:433-54.

10. O'Connell JW, Schreck C, Moles M, Badwar N, DeMarco T, Olgin J, et al. A unique method by which to quantitate synchrony with equilibrium radionuclide angiography. J Nucl Cardiol 2005; 12:441-50.

11. Wassenaar R, O'Connor D, Dej B, Ruddy TD, Birnie D. Optimization and validation of radionuclide angiography phase analysis parameters for quantification of mechanical dyssynchrony. J Nucl Cardiol 2009;16:895-903.

12. Lalonde M, Birnie D, Ruddy TD, Dekemp RA, Wassenaar RW. SPECT blood pool phase analysis can accurately and reproducibly quantify mechanical dyssynchrony. J Nucl Cardiol 2010;17:80310.

13. Uebleis C, Ulbrich M, Tegtmeyer R, Schuessler F, Haserueck N, Siebermair J, et al. Electrocardiogram-gated 18F-FDG PET/CT hybrid imaging in patients with unsatisfactory response to cardiac resynchronization therapy: Initial clinical results. J Nucl Med 2011;52:67-71.

14. Chen J, Garcia EV, Bax JJ, Iskandrian AE, Borges-Neto S, Soman P. SPECT myocardial perfusion imaging for the assessment of left ventricular mechanical dyssynchrony. J Nucl Cardiol 2011;18:685-94.

15. AlJaroudi W, Chen J, Jaber WA, Lloyd SG, Cerqueira MD, Marwick T. Nonechocardiographic imaging in evaluation for cardiac resynchronization therapy. Circ Cardiovasc Imaging 2011;4:334-43.

16. AlJaroudi W, Alraies MC, DiFilippo F, Brunken RC, Cerqueira MD, Jaber WA. Effect of stress testing on left ventricular mechanical synchrony by phase analysis of gated positron emission tomography in patients with normal myocardial perfusion. Eur J Nucl Med Mol Imaging 2012;39:665-72.

17. Ludwig DR, Friehling M, Schwartzman D, Saba S, Follansbee WP, Soman P. On the importance of image gating for the assay of left ventricular mechanical dyssynchrony using SPECT. J Nucl Med 2012;53:1892-6.

18. European Society of Cardiology (ESC), European Heart Rhythm Association (EHRA), Brignole M, Auricchio A, Baron-Esquivias G, Bordachar P, et al. 2013 ESC guidelines on cardiac pacing and cardiac resynchronization therapy: The task force on cardiac pacing and resynchronization therapy of the European Society of Cardiology (ESC) Developed in collaboration with the European Heart Rhythm Association. Europace 2013;15:1070-118.

19. Juárez-Orozco LE, Alexanderson E, Dierckx RA, Boersma HHH, Hillege JL, Zeebregts CJ, et al. Stress myocardial blood flow correlates with ventricular function and synchrony better than myocardial perfusion reserve: A nitrogen-13 ammonia PET study. J Nucl Cardiol 2016;25:797-806.

20. Chung ES, Leon AR, Tavazzi L, Sun J-P, Nihoyannopoulos P, Merlino J, et al. Results of the Predictors of Response to CRT (PROSPECT) trial. Circulation. 2008;117:2608-16. 
21. Aljaroudi W, Alraies MC, Brunken R, Cerquiera M, Jaber WA. Paradoxical septal motion from prior coronary artery bypass graft surgery does not impact left ventricular mechanical dyssynchrony by gated myocardial perfusion imaging. J Nucl Cardiol 2012;19:1190-7.

22. Van Tosh A, Votaw JR, Cooke CD, Reichek N, Palestro CJ, Nichols KJ. Relationships between left ventricular asynchrony and myocardial blood flow. J Nucl Cardiol 2017;24:43-52.

23. Kerrigan J, Shivapour D, Tuzcu EM, Sabik EM, Jaber WA. Acute left ventricular dys-synchrony during regadenason PET myocardial perfusion stress test. J Nucl Cardiol 2015;22:388-90.

24. AlJaroudi W. Early post-stress LV dyssynchrony: A new marker for significant CAD. J Nucl Cardiol 2014;21:1057-61.

25. Huang W-S, Huang C-H, Lee C-L, Chen C-P, Hung G-U, Chen J. Relation of early post-stress left ventricular dyssynchrony and the extent of angiographic coronary artery disease. J Nucl Cardiol 2014;21:1048-56.

26. Van Campen CMC, Visser FC, Van Der Weerdt AP, Knaapen P, Comans EFI, Lammertsma AA, et al. FDG PET as a predictor of response to resynchronisation therapy in patients with ischaemic cardiomyopathy. Eur J Nucl Med Mol Imaging 2007;34:309-15

27. Lehner S, Uebleis C, Schüßler F, Haug A, Kääb S, Bartenstein P, et al. The amount of viable and dyssynchronous myocardium is associated with response to cardiac resynchronization therapy: Initial clinical results using multiparametric ECG-gated [18F]FDG PET. Eur J Nucl Med Mol Imaging 2013;40:1876-83.

28. Santana C, Verdes L, Esteves F, Cooke C, Faber T, Folks R, et al. Left ventricular (LV) dyssynchrony measured by phase analysis of gated FDG PET studies predicts cardiac death in patients with ischemic cardiomyopathy. J Nucl Med Suppl 2008;1:188.

29. Aljaroudi W, Alraies MC, Menon V, Brunken RC, Cerqueira MD, Jaber WA. Predictors and incremental prognostic value of left ventricular mechanical dyssynchrony response during stress-gated positron emission tomography in patients with ischemic cardiomyopathy. J Nucl Cardiol 2012;19:958-69.

30. Cooke CD, Esteves FP, Chen J, Garcia EV. Left ventricular mechanical synchrony from stress and rest 82Rb PET myocardial perfusion ECG-gated studies: Differentiating normal from LBBB patients. J Nucl Cardiol 2011;18:1076-85.

31. Hambye A-S, Vervaet A, Dobbeleir A. Variability of left ventricular ejection fraction and volumes with quantitative gated SPECT: Influence of algorithm, pixel size and reconstruction parameters in small and normal-sized hearts. Eur J Nucl Med Mol Imaging 2004;31:1606-13.

32. Van Der Veen BJ, Scholte AJ, Dibbets-Schneider P, Stokkel MPM. The consequences of a new software package for the quantification of gated-SPECT myocardial perfusion studies. Eur J Nucl Med Mol Imaging 2010;37:1736-44.

33. Trimble MA, Velazquez EJ, Adams GL, Honeycutt EF, Pagnanelli RA, Barnhart HX, et al. Repeatability and reproducibility of phase analysis of gated single-photon emission computed tomography myocardial perfusion imaging used to quantify cardiac dyssynchrony. Nucl Med Commun 2008;29:374-81.

34. Van Kriekinge SD, Nishina H, Ohba M, Berman DS, Germano G. Automatic global and regional phase analysis from gated myocardial perfusion SPECT imaging: Application to the characterization of ventricular contraction in patients with left bundle branch block. J Nucl Med 2008;49:1790-7.

35. Okuda K, Nakajima K, Matsuo S, Kashiwaya S, Yoneyama H, Shibutani T, et al. Comparison of diagnostic performance of four software packages for phase dyssynchrony analysis in gated myocardial perfusion SPECT. EJNMMI Res 2017;7:1-9.

36. Juarez-Orozco LE, Cruz-Mendoza JR, Guinto-Nishimura GY, Walls-Laguarda L, Casares-Echeverría LJ, Meave-Gonzalez A, et al. PET myocardial perfusion quantification: Anatomy of a spreading functional technique. Clin Transl Imaging 2018;6:47-60.

37. Tang D, Yang C, Huang S, Mani V, Zheng J, Woodard PK, et al. Cap inflammation leads to higher plaque cap strain and lower cap stress: An MRI-PET/CT-based FSI modeling approach. J Biomech 2017;50:121-9.

38. Saeed IM, Coggins T, Main ML, Bateman TM. Cardiac sarcoidosis with visually normal wall motion: Role of cardiac MRI, FDG PET, and strain echocardiography. Eur Heart J Cardiovasc Imaging 2015;16:1275

39. Bravo PE, Luo HC, Pozios I, Zimmerman SL, Corona-Villalobos $\mathrm{CP}$, Sorensen L, et al. Late gadolinium enhancement confined to the right ventricular insertion points in hypertrophic cardiomyopathy: An intermediate stage phenotype? Eur Heart J Cardiovasc Imaging 2016;17:293-300.

40. Nensa F, Bamberg F, Rischpler C, Menezes L, Poeppel TD, la Fougère $\mathrm{C}$, et al. Hybrid cardiac imaging using PET/MRI: A joint position statement by the European Society of Cardiovascular Radiology (ESCR) and the European Association of Nuclear Medicine (EANM). Eur Radiol 2018;28:4086-101.

41. Wang L, Wei HX, Yang MF, Guo J, Wang JF, Fang W, et al. Phase analysis by gated F-18 FDG PET/CT for left ventricular dyssynchrony assessment: A comparison with gated Tc-99m sestamibi SPECT. Ann Nucl Med 2013;27:325-34.

42. AlJaroudi W, Alraies MC, Hachamovitch R, Jaber WA, Brunken $\mathrm{R}$, Cerqueira MD, et al. Association of left ventricular mechanical dyssynchrony with survival benefit from revascularization: A study of gated positron emission tomography in patients with ischemic LV dysfunction and narrow QRS. Eur J Nucl Med Mol Imaging 2012;39:1581-91.

43. Pazhenkottil AP, Buechel RR, Nkoulou R, Ghadri J-R, Herzog BA, Husmann L, et al. Left ventricular dyssynchrony assessment by phase analysis from gated PET-FDG scans. J Nucl Cardiol 2011;18:920-5.

44. Boogers MM, Van Kriekinge SD, Henneman MM, Ypenburg C, Van Bommel RJ, Boersma E, et al. Quantitative gated SPECTderived phase analysis on gated myocardial perfusion SPECT detects left ventricular dyssynchrony and predicts response to cardiac resynchronization therapy. J Nucl Med 2009;50:718-25.

45. Henneman MM, Chen J, Dibbets-Schneider P, Stokkel MP, Bleeker GB, Ypenburg C, et al. Can LV dyssynchrony as assessed with phase analysis on gated myocardial perfusion SPECT predict response to CRT? J Nucl Med 2007;48:1104-11.

Publisher's Note Springer Nature remains neutral with regard to jurisdictional claims in published maps and institutional affiliations. 